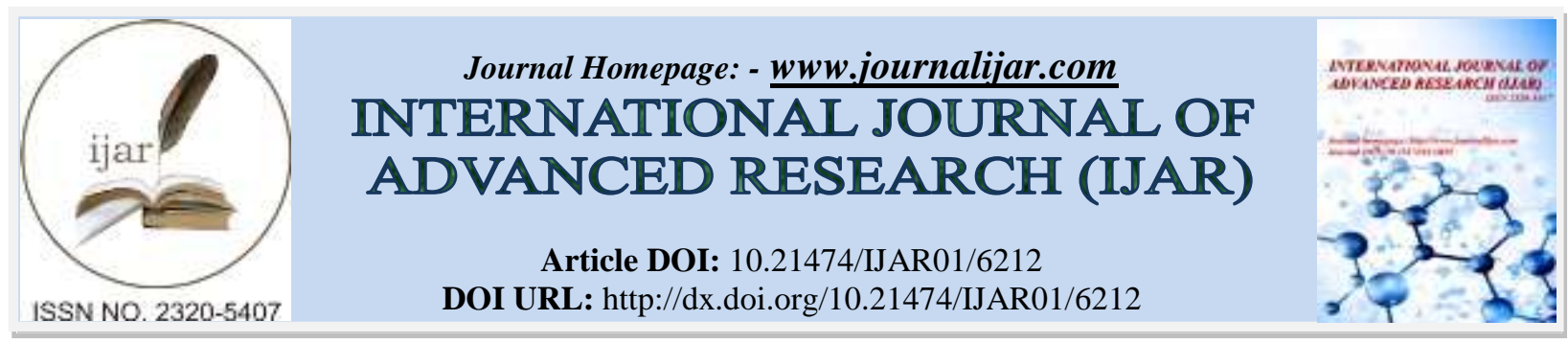

RESEARCH ARTICLE

\title{
REPORT OF ETCHANT INDUCED ORAL CHEMICAL BURN- A RARE INCIDENCE.
}

\author{
Reema Rao. MDS. \\ Department of Periodontics, A. B. Shetty Memorial Institute of Dental Sciences, Nitte (Deemed to be University), \\ Mangalore, Karnataka, India.
}

\section{Manuscript Info}

Manuscript History

Received: 04 November 2017

Final Accepted: 06 December 2017

Published: January 2018

Keywords:-

acid etching, dental bonding, chemical ulcer, orthodontics.

\begin{abstract}
Etchants are commonly used in day to day dental practice. It finds range of applications from restorative dentistry to orthodontics. Though the adverse effects of etchants on dental hard tissues and pulp have been reported but soft tissue injuries have been rarely reported.In restorative dentistry rubber dam application prevents any chances of mucosal damage due to accidental contact with this chemical agent. This paper reports a chemical burn occurred during an orthodontic procedure. It highlights the rare instance of chemical burn due to phosphoric acid etchant; it also provides a detailed treatment protocol and follow-up of such rare injury.
\end{abstract}

Copy Right, IJAR, 2018,. All rights reserved.

\section{Introduction:-}

Oral burns have been documented to be caused by a variety of means from heat, cold, radiation, electrical and chemical. ${ }^{1}$ Chemical injuries of the oral soft-tissues may readily occur due to the large number of chemical substances such as drugs and various agents, which come in contact with the oral cavity. ${ }^{2}$ The severity and extent of lesions caused by chemical agents depends on the concentration, type and quantity of the substance, as well as on the time of contact with the oral soft-tissues. ${ }^{3}$ In the oral cavity, chemical substances cause diffuse erosive lesions ranging from simple desquamation to complete obliteration of the oral mucosa with extension into the basement membrane and to the submucosa. ${ }^{4}$

Buonocuore in 1955, introduced the standard protocol to remove the smear layer for successful bonding which is popularly known as acid etching. ${ }^{5}$ Phosphoric acid is used as an etching material in adhesive dentistry. It has also been widely used in restorative dentistry and for bonding orthodontic brackets. Currently available etchants are 30 to $40 \%$ phosphoric acid, this chemical is potentially caustic in high concentration. This chemical agent used in the oral cavity should not come into contact with the gingiva or any other soft tissues. Unfortunately, rare cases of unintentional spillage of phosphoric acid have been reported. ${ }^{6,7}$

\section{Case Report -}

A female patient aged 22 years visited Oral Medicine department with the chief complaint of irregularly placed lower front teeth. She was diagnosed with Angles class I malocclusion with crowding in the lower anteriors. She was advised to undergo orthodontic treatment. During her treatment phase $37 \%$ Phosphoric acid which is used for etchant before the placement of brackets, accidentally fell on the dorsal surface of the tongue. She was asked to rinse her mouth with water immediately by the orthodontist who was treating her. Later she was referred to the 
department of Periodontics for the oral prophylaxis of lower arch before the placement of brackets. She reported of burning sensation over the tongue.

On intraoral examination a reddish lesion surrounded by whitish halo was noticed on the dorsal surface of the tongue (Figure 1). The reddish lesion was irregular in shape and measured about $3 \mathrm{cms} \mathrm{X} 1 \mathrm{~cm}$ in size. The surrounding area had normal papillae .The lesion was debrided using saline dipped cotton swabs. Topical lignocaine $2 \%$ gel was the applied over the eroded area. The patient was advised to frequent saline rinse and topical lignocaine application four times a day for four days. The patient was also advised to have a bland diet for a week. When the patient was reviewed after a week, she was completely asymptomatic. On examination complete healing of the lesion was observed and the dorsum of the tongue was covered by normal papillae (Figure 2). The patient was reviewed for three successive weeks with no evidence of any symptoms or clinical changes.

\section{Discussion:-}

Esthetics has been an indispensable element in human life since centuries. The elimination of esthetic problems substantially helps in gaining the confidence and self-expression. In addition to the different departments dealing with esthetics in medicine, orthodontists also makes an arrangement to eliminate the various esthetic and functional concerns. Dental arrangements mostly involve the use of fixed orthodontic treatment. Etching of the enamel is the foremost procedure in the orthodontics before the placement of brackets. In 1955, Buonocore applied 85\% phosphoric acid to enamel and became a pioneer in by providing a method for bonding acrylic structures by etching on enamel. ${ }^{5}$ The irregular enamel surface created by dissolving hydroxyapatite crystals permits penetration of the fluid adhesive components, and this penetration provides micromechanical retention. ${ }^{8}$ Acid etching of enamel appears to improve retention by selectively eroding certain hydroxyapatite formations and facilitating penetration by the development of resin tags ${ }^{8}$. Stanley mentioned that inappropriate acid etching procedures using $50 \%$ phosphoric acid could lead to ulceration and sloughing of oral tissues. ${ }^{9}$ In current practice, $37 \%$ orthophosphoric acid gel or solution is applied to enamel for 30 seconds, and the minerals on the enamel surface are dissolved. In this report $37 \%$ phosphoric acid was used. It is generally known that even short term exposure to caustic agents is capable of inducing tissue necrosis which can lead to a localized mild erythema. ${ }^{11}$ The clinical appearance of the chemical burns in most cases depends on the severity of the tissue damage. Longer exposure or higher concentration of solution causes epithelial necrosis and shedding. ${ }^{12}$ In this case the duration of exposure was short and hence the resultant lesion exhibited form of mild erythema. Clinical reports have singled out certain chemical substances as cause of oral mucosal burn. ${ }^{2}$ The contact of the chemical with the oral cavity can readily cause inflammation, ulcerations and depending on its location can cause difficulty in phonation, swallowing and mastication. ${ }^{13}$ Only burning sensation and mild discomfort was reported in this patient.

To prevent contact of caustic and potentially harmful chemicals such as orthophosphoric acid with the oral mucosa during treatment procedures, tooth isolation is essential. The use of cotton rolls is definitely a more effective method of ensuring a dry field as well as preventing accidental contact of etchant and sealant material with the mucosa. ${ }^{14}$

In most cases, treatment is mainly symptomatic. The treatment for chemical burns is the application of a protective coating such as Orabase with or without steroids and initiation of a bland diet. ${ }^{15,16}$ In this case similar treatment was implemented. Permanent removal of the agent has been suggested as a preliminary measure in iatrogenic or accidental injury case. ${ }^{2}$ Irrigation is the emergency treatment choice to minimize the product effect and current therapy with steroids results in a very favorable prognosis. ${ }^{13}$

\section{Conclusion:-}

The burn lesions in the oral cavity can occur at dental offices and homes. Accidentally, dentists may cause chemical burns in the oral cavity when using the medications or caustic dental materials. So it is the duty of the dental practitioner to know their responsibility about the possible damage to the tooth and the surrounding tissues when using various chemicals and to prevent such damage by protective methods and tissue management. 


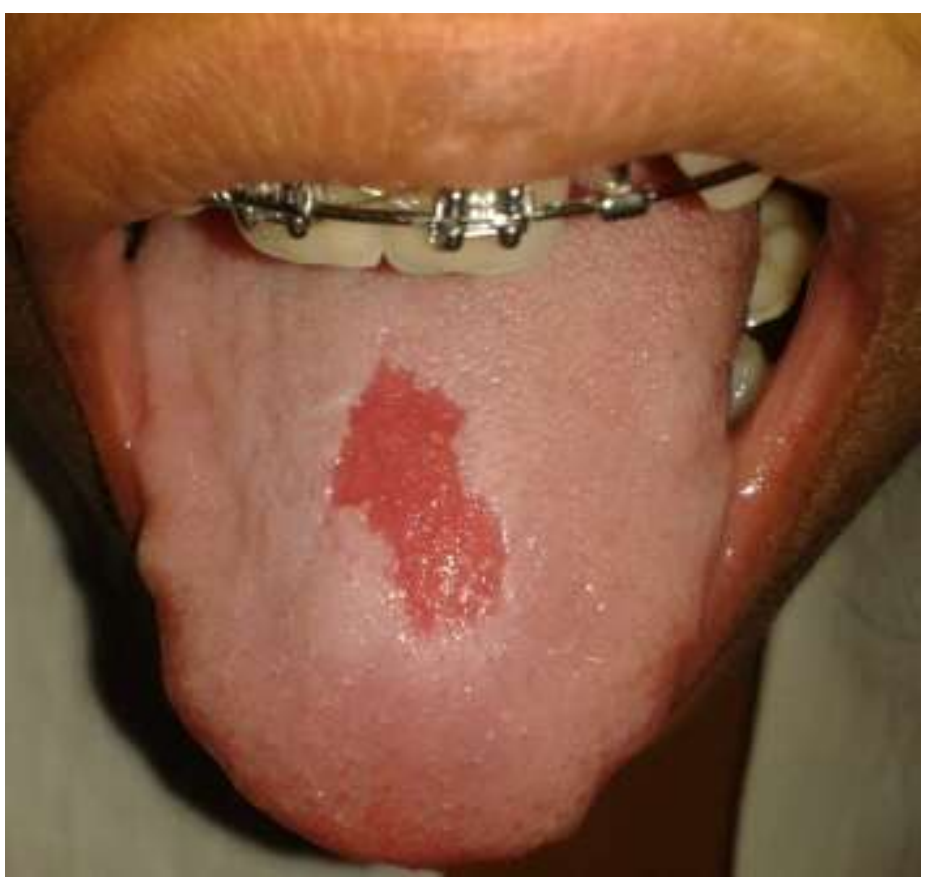

Figure 1:- Photograph showing the reddish lesion surrounded by whitish halo.

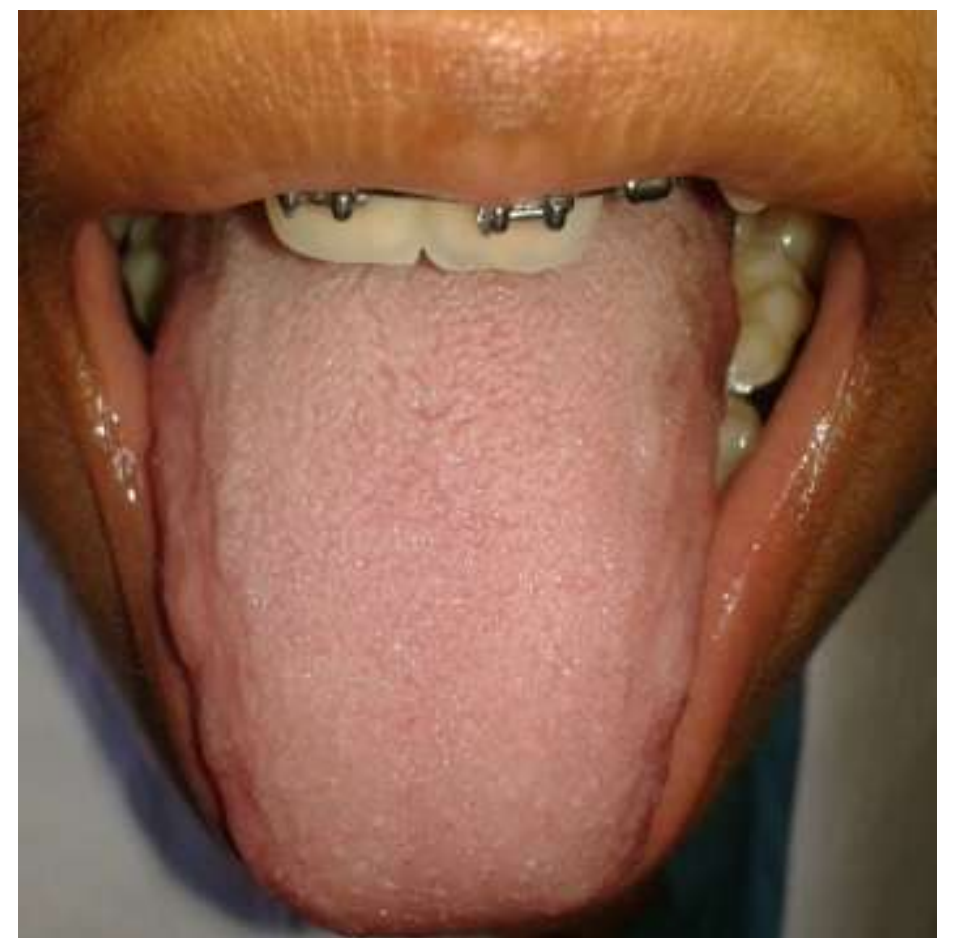

Figure 2:- Photograph showing complete healed lesion after one week. 


\section{References:-}

1. Baruchin, Abraham M, Lustig, Joseph P, Nahlieli, Oded, Neder, Amos. Burns of the Oral Mucosa: Report of 6 Cases. J Cranio-Max. Fac. Surg. 1991; 19: 94-96.

2. Shetty K. Hydrogen peroxide burn of the oral mucosa. Ann Pharmacother. 2006; 40:351.

3. Mamede RC, de Mello Filho FV. Ingestion of caustic substances and its complications. Sao Paulo Med J. 2001; 119: 10-5.

4. Rawal SY, Claman LJ, Kalmar JR, Tatakis DN. Traumatic lesions of the gingiva: a case series. J Periodontol. 2004; 75: 762-9.

5. Buonocore MG. A simple method of increasing the adhesion of acrylic filJing materials to enamel surfaces. $\mathrm{J}$ Dent Res 1955; $34: 849-53$.

6. Huang TH, Tsai CY, Chen SL, Kao CT. An evaluation of the cytotoxic effects of orthodontic bonding adhesives upon a primary human oral gingival fibroblast culture and a permanent human oral cancer cell-line. $\mathrm{J}$ Biomed Mater Res 2002; 63(6): 814-21.

7. Szep S, Kunlel A, Ronge K, Heidemann D. Cytotoxicity of modern dentin adhesives - in vitro testing on gingival fibroblasts. J Biomed Mater Res 2002; 63(1): 53-60.

8. Silverstone LM, Saxton CA, Dogan IL, Fjerskov D. Variation in the pattern of acid etching on human dental enamel examinedby scanning electron microscope. Caries Res. 1975; 9: 373-87.

9. Stanley HR. Effects of dental restorative materials: local and systemic responses reviewed. J Am Dent Assoc $1993 ; 124: 76-80$.

10. Oliver RG. The effects of differing etch times on the etch pattern on enamel of unerupted and erupted human teeth examined using the scanning electron microscope. Br J Orthod 1987; 14: 105-7.

11. Regezi JA and Sciubba J. Ch. 3 : White lesions. In: Regezi JA, Sciubba J(eds) Oral pathology Clinicalpathologic. 2nd. edn., Pennsylvania : Saunders, 1993 : 116-17.

12. Tiwari NG, Bajaj AN. Formulation development of eucalyptus oil microemulsion for intranasal delivery. Indian J Pharm Sci 2007; 69: 731-3.

13. Yano K, Hata Y, Matsuka K, Ito O, Matsuda H. Effects of washing with a neutralizing agent on alkaline skin injuries in an experimental model. Burns 1994; 20: 36-9.

14. Direct bond brackets: cotton roll versus rubber dam isolation Maury Heringer, Marco Antonio Almeida, and Jose Augusto Miguel The Angle Orthodontist Sep 1993, Vol. 63, No. 3 (September 1993) pp. 231-234.

15. Wood NK, Goaz PW. Chemical Burns. In: Differential Diagnosis of Oral Lesions. 4th ed. St. Louis: Mosby Year Book; 1991; 68-70, 144-145.

16. Baruchin AM, Lustra JP, Nahlieli O, Neder A. Burns of the Oral Mucosa. J Craniomaxilofac Surg. 1991; 19: 94-6. 